\title{
ПОНЯТИЕ КОММУНИКАЦИИ В НЕМЕЦКОЙ КОММУНИКАТИВНОЙ ФИЛОСОФИИ
}

\begin{abstract}
С.В. Лебедева
На сегодняшний день изучение общества как социальной системы невозможно без анализа процессов коммуникации, которые пронизывают все сферы общественной жизни и отношения между людьми. В условиях формирования глобального мирового сообщества между социумами размываются границы, с одной стороны, но, в то же время, возникает опасность потери суверенитета, с другой. Только в сфере всесторонней коммуникации возможно избежание конфликтов. Отношения между интегрированными общественными структурами строятся в этом случае по модели субъект-субъектных отношений в отличие от субъъект-объектных.

Коммуникация - универсальное приобретение человечества и универсальная форма общественного существования. По мнению Л. Ситниченко, ни одно общественно значимое дело невозможно вне его коммуникативного, опосредованного публичным обсуждением признания, то есть вне легитимации [4, с. 13]. Демократично организованное сообщество должно достичь единства, консенсуса. Это возможно посредством дискурса, который является практикой коммуникативных взаимоотношений с целью достижения социального согласия и предотвращения кризисного состояния общества.

Современная западная философия пытается отыскать возможные пути преодоления такого социального кризиса. Концепции ее представителей претендуют на открытие новых форм социальной интеграции, согласования личностных и общественных интересов, отдельных целей и ценностей. Это выразилось, в частности, в немецкой философии и социологии в смене парадигм. Одной из таких парадигм после «бытия»
\end{abstract}


и «сознания» становится парадигма коммуникации. Она, по мнению А. Ермоленко, опирается на трансцендентальную (идеальную) языковую прагматику и определяет одно из самых влиятельных направлений современной западной фнлософской мысли - коммуникативную философию [1, с. 19], которую интерпретируют также как коммуникативную или дискурсивную этику, универсальную прагматику, практическую философию.

В коммуникативной философии представлены, на наш взгляд, два различных подхода к пониманию коммуникации, способа ее функционирования и роли в социуме.

Одна теоретическая позиция представлена в немецкой коммуникативной философии К.-О. Апелем, Ю.Хабермасом, В.Хёсле и их последователями. Она базируется на трансцендентальной прагматике и берет за основу учения немецкой классической философии, в частности, априоризм Канта.

Особ́енно отчетливо это представлено в работах К.-О. Апеля, который одним из первьх определил коммуникацию как основу (Letzbegründung) сознания, познания и общественного бытия. Данное утверждение стало этапным для современной философской мысли и послужило основанием для так называемого коммуникативного поворота в философии. Бесспорной заслугой Апеля является его попытка объединить традиции англо-американской философии (прагматической и аналитической) и философии континентальной, европейской (герменевтики, философии М.Хайдеггера, классической трансцендентальной философии), изложенная в его произведении «Трансформация философии».

Опираясь на достижения предшественников, К.-О. Апель обосновывает понятие «априори коммуникации». Он считает, что каждый коммуникативный акт человека (а вне коммуникации человек не существует сознательно) уже - a priori, еще до реального осуществления предусматривает собственно коммуникативность $[9$, с. 60]. Также он вводит понятия априори аргументации и идеального сообщества (сообщества аргументирующих). Апель считает, что каждый аргументирующий всегда имеет в виду то обстоятельство, что в ходе дискурса он добудет истину. Сама же ситуация аргументации не может привести к обману $[4$, с.22]. Осмысленная аргументация возможна только в неограниченном коммуникативном сообществе, в котором каждый способный говорить, пребывая в истине, сохраняет такое положение вещей путем «трансцендентальной рефлексии» $[4$, с. 24].

Несмотря на то, что Апель высоко оценивает свою теорию «настоя- 
щей коммуникацин» и «коммуникативного сообщества», она вызывает сомнения и критику. Существенным недостатком его концепции, как нам представляется, является ее чрезмерная абстрактность и упрощение реальных процессов коммуникации. Это упрощение содержится в утверждении Апеля о том, что в сравнении с априори аргументацией или идеальным сообществом, все другие материальные и экзистенциальные предпосылки реального взаимопонимания являются второстепенными [9, с. 62].

По нашему же мнению, даже если предположить существование априори аргументации, возможность обмана или непонимания не исключается в процессе коммуникации, так как именно материальными предпосылками она и будет обусловлена. Поэтому невозможно также и существование идеального сообщества в реальном мире.

Ученик и последователь К.-О. Апеля Ю. Хабермас является наиболее ярким представителем обозначенной нами первой теоретической позиции. Он внес существенный вклад в коммуникативную философию и считается одним из ведущих современных философов данного направления. Результатом его социально-философских исследований стала «теория коммуникативного действия», с помощью которой он хотел бы, с одной стороны, обосновать теорию рационализации общества М. Вебера, с другой - проанализировать основные вопросы этики, теории языка и разумности действия.

Философия коммуникации Ю. Хабермаса начинается с положения о том, что существующее общество - это открытая система, которая объединена в единое целое господствующим в ней языком как главным средством общения. Также общество объединяют нормы и ценности, закрепленные в этом языке. В то же время Хабермас рассматривает язык как вид метаинститута, от которого зависят все другие общественные институты, поскольку социальное действие осуществляется исключительно в повседневной языковой коммуникации.

Данные положения изложены Ю. Хабермасом в его работе « $\mathbf{K}$ реконструкщии исторического материализма». Автор утверждает, что «уровень социокультурного развития общества характеризуется уровнем развития языковой коммуникации», а повседневная коммуникативная практика - главный показатель уровня развития общества как «жизненного мира» [11, с. 132].

По мнению Л.А. Ситниченко, «теория коммуникативного действия» Ю. Хабермаса опирается на его теорию социального действия. Социальное действие - это опосредованная традициями взаимосвязь в повседневной языковой коммуникации $[4$, с. 32$]$. Взаимодействие людей 
в обществе осуществляется, прежде всего, как языковое взаимодействие, направленное на достижение взаимопонимания между участниками коммуникации. Ю. Хабермас в работе «Моральное сознание и коммуникативное действие» утверждает, что коммуникативными можно назвать такие интеракции, в которьх их участники согласуют и координируют планы своих действий, при этом достигнутое в том или ином случае согласие измеряется интерсубъективным признанием притязаний на значимость. В случае, как считает автор, когда процессы взаимопонимания идут в әксплицитной языковой форме, акторы, разговаривая о чем-либо друг с другом, своими речевыми действиями выдвигают притязания на значимость, а именно притязания на истинность, на правильность и на правдивость своих высказываний $[8$, с. 92]. В отношении притязаний на истинность и правильность, по мнению Хабермаса, говорящий может соблюсти свои гарантии дискурсивным образом, то есть посредством оснований, а в отношении притязаний на правдивость - соответствующим поведением. При этом «истинностные притязания имеют место только в речевых действиях, тогда как притязания на нормативную значимость содержатся, прежде всего, в нормах и лишь вторичным, производным образом - в речевых действиях» $[8$, с. 95$]$.

В этой связи возникает вопрос, что мокет побудить слушателя положить в основу своего действия предпосылку, что говорящий так же серьезно относится к его притязаниям на значимость и должен принять выдвинутые обязательства? В.Н. Фурс в «Философии незавершенного модерна Юргена Хабермаса», отвечая на этот вопрос, цитирует тезис Хабермаса: «В конечном счете говорящий может иллокутивно воздействовать на слушателя, а последний, в свою очередь, на говорящего потому, что типичные для речевого действия обязательства связаны с когнитивными и доступными проверке притязаниями на значимость, то есть потому, что взаимные обязательства имеют рациональную основу» $[6$, с. 60$]$.

По мнению Хабермаса, «внутренне присущая коммуникативной практике рациональность обнаруживается в том, что коммуникативно достигаемое согласие должно, в конечном счете, опираться на определенные основания. И рациональность тех, кто участвует в этой коммуникативной практике, оценивается по тому, могут ли они обосновать свои выражения при подходящих условиях. Следовательно, рациональность, внутренне присущая повседневной коммуникативной практике, указывает на практику аргументапии как на ту инстанцию, апелляция к которой позволяет продолжать коммуникативную практику 
другими средствами, когда некоторое разногласие не может быть предотвращено рутиной повседневности и вместе с тем не должно решаться непосредственным или стратегическим использованием насилия» $[10$, с. 28]. Коммуникация может оставаться ненарушенной до тех пор, пока все ее участники признают, что взаимно выдвигаемье притязания на значимость они выдвигают верно. Если не удается достигнуть согласия в непосредственной коммуникативной практике, то в качестве альтернативы прекращению коммуникации или переходу к инструментальному использованию языка (для силового воздействия на партнеров) выступает дискурс.

Дискурс представляет собой способ диалогически-аргументативного испытания спорного притязания на значимость с целью достижения общезначимого согласия. Дискурс, считает Хабермас, - такой вид языковой коммуникации, который организован комплексом строгих правил:

1. Участие в дискурсе открыто для любого способного к речи субъекта при его полном равноправии со всеми остальными участниками дискурса.

2. В дискурсе запрещается осуществлять какое-либо принуждение в целях достижения согласия.

3. Участники дискурса вправе действовать лишь на основе мотива достижения кооперативного и аргументированного согласия. По отношению к фактическим коммуникативным практикам дискурс выступает в качестве «идеальной речевой ситуации».

Хабермас отмечает, что феномен ложного согласия, если его рассматривать с философской точки зрения, следует понимать не как результат внешних воздействий, а как закономерное следствие принуждения, заложенного в самой структуре коммуникации. Иными словами, оно является порождением систематического нарушения коммуникации - нарушения одного или более правил дискурса. Структура коммуникативных практик только тогда не содержит никакого принуждения, если всем возможным участникам предоставлено симметричное распределение шансов выбирать и осуществлять речевые акты, когда в коммуникации господствует лишь специфическое «ненасильственное принуждение» лучшего аргумента.

Приведенные рассуждения можно обобщить таким образом, что «коммуникативное действие» является основным в теории Хаберма- 
са. Жизненный мир в его понимании - поле, в котором всегда пребывают действующие индивиды, это основа коммуникативного действия. Свое концентрированное выражение жизненный мир получает в процессах взаимопонимания, так как он,- прежде всего, «образец истолкований», которые передаются с помощью традиций и языка [10, c. 192]. Следовательно, язык и культура являются основополагающими факторами жизненного мира; они имеют, по мнению Хабермаса, трансцендентальный характер.

Центральным понятием в теории Ю. Хабермаса является понятие «коммуникативной рациональности». Ее сердцевина - «не вынужденная, объединяющая, рождающая консенсус сила аргументирующей речи» $[5$, с. 140], которая есть «центральное переживание» в жизни человеческого существа. Согласно Хабермасу, это центральное переживание внутренне присуще общественной жизни человека: «Коммуникативный разум непосредственно вовлечен в процессы общественной жизни в той мере, в какой акты взаимного понимания берут на себя роль механизма координации действий» [5, с. 140]. Поэтому Хабермас рассматривает коммуникацию как субъект-субъектные отношения, характерные для открытого общества. Он считает коммуникацию результатом деятельности субъектов, которая осуществляется внутри системы и направлена на достижение взаимопонимания в ходе дискурса.

Вторая теоретическая позиция, противоположная хабермасовской коммуникативной теории, представлена Никласом Луманом. Он критикует теорию Хабермаса и предлагает иной взгляд на понимание коммуникации, основанный на дифференциации общества как социальной системы и окружающего мира.

Луман считает, что «общество - это коммуникативно закрытая система» [3, с. 101]. Но данное утверждение не подразумевает ничего из того, что могло бы пониматься как «каузальная изоляция, отсутствие контакта или же абсолютная замкнутость системы» [3, с. 71]. Как утверждает Луман, «всякая открытость основывается на закрытости системы» и представляет социальную систему как оперативно закрытую, состоящую из собственных операций. Общество порождает коммуникацию через коммуникацию. Его динамика состоит в воздействии коммуникации на коммуникации и в этом смысле - в трансформации тех или иных актуальных различений и обозначений; она никогда не выражается в преобразованиях окружающего мира. Вещи нельзя упорядочить речами, как, впрочем, их нельзя и мысленно устранить или трансформировать.

Разделяя научные взгляды нейробиологов Франциско Варелы и 
Умберто Матураны на природу живых и социальных систем, Луман применяет в своих работах биологическую концепцию «аутопойезиса» (autopoesis).

Аутопойетические системы, по мнению автора, представляют собой такие системы, которые в сети своих элементов порождают не только свои структуры, но и сами элементы, из которых они состоят. Эти элементы (если их рассматривать во времени, то речь идет об операциях), из которых состоят аутопойетические системы, не существуют независимо от них. Они не просто связаны между собой и вступают в единое целое. Они порождаются самой системой именно благодаря тому, что признаются как различия [3, с. 68]. Элементы-это информации, различия, которые производят различие в системе. Поэтому они являются единицами применения для производства следующих единиц применения, для которых в окружающем мире системы не существует никакого соответствия.

Коммуникация, предполагающая аутопойетическую операцию коммуникации, порождает общество, однако, считает Луман, из этого еще не вытекает, какое именно это будет общество. Тем самым он отказывается от онтологического способа объяснения системы, а вместе с ним и от дифференциации «субъект-объект».

«Общество является системой, определяющей себя - полностью и исключительно - при помощи себя самой» [3, с. 102]. По мнению Лумана, все, что определяется как коммуникация, должно быть определено через коммуникацию. Все, что предстает в опыте в виде реальности, вытекает из противостояния одной коммуникации и некоей другой коммуникации, а не из принудительного характера как-то уже наличествующего окружающего мира.

Являясь системой коммуникации, общество может коммуницировать только в себе самом, но никак не с самим собой и не со своим окружающим миром. Ведь ни оно само, ни его окружающий мир не могут еще раз воплотиться в этом обществе как бы в виде его партнера, в виде адреса для коммуникации. Подобный опыт, считает Луман, означал бы говорение в пустоту, он не смог бы запустить общественный аутопойезис, и, следовательно, на этом бы и закончился. Ведь общество возможно лишь как аутопойетическая система [3, с. 103].

Если отвлечься от того, что фактически система общества уже существует, а коммуникация репродуцируется через коммуникацию, то само это положение вещей представится маловероятным. Луман подчеркивает, что «вероятной себя делает лишь сама коммуникация» $[2$, c. 1]. Совершаться как единичное событие она не может. Любая ком- 
муникация предполагает другие операции подобного типа, на которые она может реагировать и которые она может стимулировать. Это значит, что подсоединение коммуникации к коммуникации не может быть произвольным или случайным. Должны иметься определяющие ожидания вероятности - иначе аутопойезис коммуникации невозможен.

Связано это с тем утверждением Лумана, что коммуникация осуществляется посредством синтеза трех различных селекций, а именно: селекции информации, селекции сообщения этой информации и селективного понимания или непонимания этого сообщения и его информации. Ни один из этих компонентов не может иметь место лишь для себя одного. Они производят коммуникацию лишь вместе. При этом коммуникация осуществляется в том случае, если, прежде всего, понято различие сообщения и информации. Это отличает ее от голого восприятия поведения другого. Однако не только информация и сообщение, но и понимание является селекцией. Оно - не голое дублирование сообщения в чужом сознании, а предпосылка присоединения следующей коммуникации в коммуникативной системе, то есть условие аутопойезиса социальной системы. По мнению Лумана, три компонента - информацию, сообщение и понимание - не следует интерпретировать ни как функции, ни как акты, ни как горизонты притязаний на значимость. Эти компоненты не могут существовать независимо и объединяться субъектом, так как, считает автор, нет никакой информации, нет никаких сообщений, нет никакого понимания вне коммуникации. Поэтому снова следует вьвод - система коммуникации является полностью закрытой системой, которая сама производит компоненты, из которых она состоит.

Дать полную характеристику теоретической позиции Н. Лумана и ее соотношения с хабермасовской в рамках одной статьи невозможно в виду сложности и оригинальности его понимания коммуникации. Но, на основе вышеизложенного, можно выявить некоторые кардинальные различия между данными позициями, сведя их в следующую таблицу:

\begin{tabular}{|l|l|}
\hline По Ю. Хабермасу & По Н. Луману \\
\hline \hline Общество - коммуникативно & Общество - коммуникативно \\
открытая система. & $\begin{array}{l}\text { замкнутая, но не изолирован- } \\
\text { ная система. }\end{array}$ \\
\hline
\end{tabular}




\begin{tabular}{|c|c|}
\hline $\begin{array}{l}\text { Коммуникация - субъект- } \\
\text { субъектные } \\
\text { слотношения, обу- } \\
\text { действием. }\end{array}$ & $\begin{array}{l}\text { Коммуникация порождает } \\
\text { коммуникацию и включает } \\
\text { три компонента: информацию, } \\
\text { сообщения, понимание, кото- } \\
\text { рые взаимосвязаны, взаимо- } \\
\text { обусловлены и не существуют } \\
\text { вне коммуникации. }\end{array}$ \\
\hline $\begin{array}{l}\text { Основа коммуникации - } \\
\text { коммуникативная рациональ- } \\
\text { ность. }\end{array}$ & $\begin{array}{l}\text { Теория рациональности ком- } \\
\text { муникативного действия оши- } \\
\text { бочна уже чисто эмпирически. }\end{array}$ \\
\hline $\begin{array}{l}\text { Коммуникация, основанная на } \\
\text { рациональном коммуникатив- } \\
\text { ном действии и на аргумен- } \\
\text { тированности высказывания, } \\
\text { приводит к достижению согла- } \\
\text { сия, относительно притязаний } \\
\text { на значимость. }\end{array}$ & $\begin{array}{l}\text { Bсе коммуникации рискован- } \\
\text { ны. }\end{array}$ \\
\hline $\begin{array}{l}\text { Цель коммуникации - взаимо- } \\
\text { понимание, достигаемое в ходе } \\
\text { дискурса. }\end{array}$ & $\begin{array}{l}\text { Коммуникация не имеет ника- } \\
\text { кой цели, а лишь порождает } \\
\text { коммуникации. }\end{array}$ \\
\hline $\begin{array}{l}\text { Общество функционирует на } \\
\text { стыке системы (как совокупно- } \\
\text { сти социальных институтов) и } \\
\text { жизненного мира, который но- } \\
\text { сит трансцендентальный хара- } \\
\text { ктер. }\end{array}$ & $\begin{array}{l}\text { Дифференциация общества } \\
\text { как закрытой системы (со- } \\
\text { циальных институтов) от } \\
\text { окружающего мира (природы } \\
\text { и культуры). }\end{array}$ \\
\hline
\end{tabular}

Рассмотренные различия дают нам основание заключить, что теоретическая позиция Ю. Хабермаса основана на коммуникативной рациональности, что в некоторой степени идеализирует и выводит на первый план субъекта - носителя коммуникации. Роль общества при этом носит второстепенный характер. Н. Луман, в противоположность Ю. Хабермасу, на первый план выдвигает общество как систему коммуникаций, которые обусловливают друг друга. При этом понятие субъекта теряет свою значимость. В этой связи, как нам представляется, обе теоретические позиции не лишены существенных недостатков и требуют дальнейшего исследования и анализа. По нашему мнению, этот анализ должен быть направлен на выяснение тех аспектов функционирования общества как системы, которые невозможны без процессов коммуникации. Саму же коммуникацию необходимо исследо- 
вать как взаимодействие субъектов.

\section{1 Литература}

[1] Єрмоленко А.М. Комунікативна практична філософія.-К.: Либідь, 1999.

[2] Луман Н. Медиакоммуникации. - М.: Логос, 2005.

[3] Луман Н. Общество как социальная система.-М.: Логос, 2004.

[4] Ситниченко Л.А. Першоджерела комунікативної філософії. - K.: Либідь, 1996.

[5] Фликбере Б. Хабермас и Фуко: мыслители для гражданского общества // Вопросы философии. - 2002. - № 2. - С. 137-157.

[6] Фурс B.Н. Философия незавершенного модерна Юргена Хабермаса.- Мн.: Экономпресс, 2000.

[7] Хабермас Ю. Демократия. Разум. Нравственность: Лекции и интервью. - М.: Наука, 1992.

[8] Хабермас Ю. Моральное сознание и коммуникативное действие. СПб.: Наука, 2000.

[9] Apel K.-O. Transformation der Philosophie.-Bd. 1.-Fr./ M., 1973.

[10] Habermas $J$. Theorie des kommunikativen Handels. - Bd. 1. - Fr./M., 1995.

[11] Habermas $J$. Zur Rekonstruktion des historischen Materialismus. Fr./M., 1976. 